\title{
Commentary: No harm, no foul-Staged pulmonary artery banding in complete canal defects
}

\author{
Aaron Eckhauser, MD, MS
}

\author{
From the Division of Cardiothoracic Surgery, Department of Surgery, University of Utah, Salt Lake City, Utah. \\ Disclosures: Author has nothing to disclose with regard to commercial support. \\ Received for publication Sept 26, 2019; revisions received Sept 26, 2019; accepted for publication Sept 26, 2019; \\ available ahead of print Oct 25, 2019. \\ Address for reprints: Aaron Eckhauser, MD, MS, 100 N Mario Capecchi Dr, Suite 2200, Salt Lake City, UT 84113 \\ (E-mail: Aaron.eckhauser@hsc.utah.edu). \\ J Thorac Cardiovasc Surg 2020;159:1507 \\ 0022-5223/\$36.00 \\ Copyright (C) 2019 by The American Association for Thoracic Surgery \\ https://doi.org/10.1016/j.jtcvs.2019.09.116
}

In this month's edition of The Journal of Thoracic and Cardiovascular Surgery, Devlin and colleagues ${ }^{1}$ present their work studying the efficacy of pulmonary artery banding (PAB) in patients with complete atrioventricular septal defect (AVSD). In an analysis of data from the Congenital Heart Surgeon's Society AVSD cohort, Devlin and colleagues ${ }^{1}$ studied 50 patients with an AVSD who underwent a PAB (median age, 1.1 months) as a staged procedure before a biventricular repair or a univentricular versus biventricular decision. Although this contemporary cohort is relatively small and spread across 28 institutions, there is much to be gleaned from this experience.

First, staged PAB in patients with a planned biventricular repair is very effective. The 33 patients $(66 \%)$ in the PAB cohort who ultimately underwent a biventricular repair had a 93\% survival at 4-year follow-up, compared with a $91 \%$ survival in the cohort of 333 patients (initial AVSD cohort) who underwent a primary biventricular repair. These results simultaneously provide encouragement that staged banding with planned biventricular repair is equally effective as primary repair and caution that the midterm mortality was $9 \%$ in a contemporary series of patients with complete AVSD. In 2018, Buratto and associates ${ }^{2}$ reported a similar cohort of patients with AVSD undergoing PAB who had a $78 \%$ survival at 5 years. When they examined patients who underwent an early PAB $(<3$ months of age), however, survival was improved to $88 \%{ }^{2}$. These complementary studies support the efficacy of staged PAB in patients with a balanced AVSD and planned biventricular repair.

A similarly important finding in this study is the variable and unpredictable effect of PAB on the function of the common atrioventricular valve. Unfairly, but not uncommonly, PAB is abandoned for fear of worsening atrioventricular valve function. In the study of Devlin and colleagues, ${ }^{1} 14$ patients had a decrease in common atrioventricular valve regurgitation after $\mathrm{PAB}$ and $10 \mathrm{had}$ an increase. In the overall cohort, however, atrioventricular valve regurgitation did not change significantly with time. The relatively small

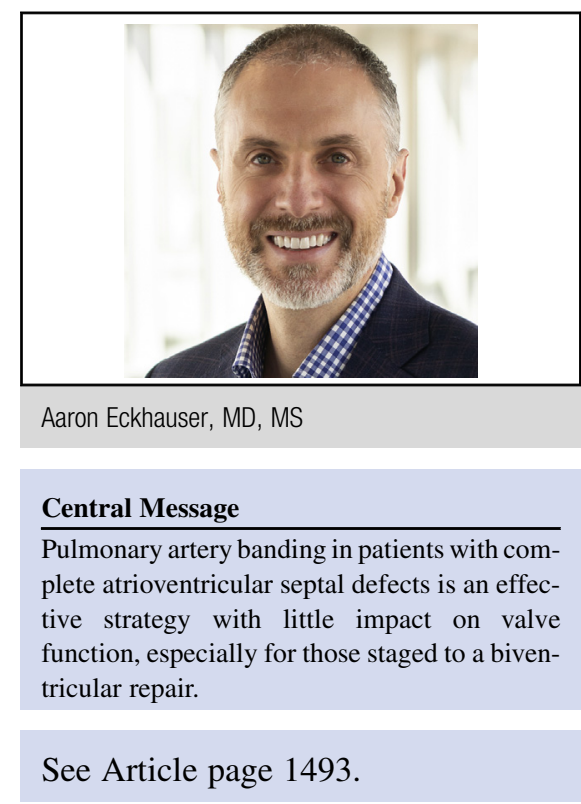

sample size prohibited subgroup analysis and identification of factors predictive of any direct effect of PAB on valve function.

An important limitation of the study of Devlin and colleagues ${ }^{1}$ is the small sample size and dilution of PAB experience across 28 centers. It is important to understand how a similar technique and consistent achievement of objective hemodynamic metrics of band adequacy (oxygen saturations, postbanding pulmonary artery pressures etc) specifically correlate with mortality and atrioventricular valve function. Similarly, although this study did not contain any neonatal repairs, it is important to compare prospectively the outcomes of competing early surgical interventions, namely neonatal $\mathrm{PAB}$ versus complete neonatal repair.

Despite study limitations, this excellent article supports the selective role of PAB in the treatment of patients with a complete AVSD. When properly chosen, the majority of these patients can undergo eventual biventricular repair with excellent midterm survival.

\section{References}

1. Devlin PJ, Jegatheeswaran A, McCrindle BW, Karamlou T, Blackstone EH Williams WG, et al. Pulmonary artery banding in complete atrioventricular septal defect. J Thorac Cardiovasc Surg. 2020;159:1493-503.e3.

2. Buratto E, Khoo B, Ye XT, Daley M, Brizard CP, d'Udekem Y, et al. Long-term outcome after pulmonary artery banding in children with atrioventricular septal defects. Ann Thorac Surg. 2018;106:138-44. 